\title{
Estrategias financieras para mejorar las cuentas por cobrar en la empresa Aquasport
}

\section{S.A.C.}

Katy Morales García

ORCID 0000-0002-7531-1490

Universidad Privada Norbert Wiener, Lima Perú

Kattymorales.9208@gmail.com

Irma Milagros Carhuancho Mendoza

ORCID 0000-0002-4060-5667

Universidad Privada Norbert Wiener Lima Perú

irmamilagros@yahoo.com

Fecha de recepción: 5 de enero de 2020

Fecha de aceptación: 05 de abril de 2020

\section{Resumen:}

La presente investigación tuvo por objetivo proponer estrategias financieras para mejorar las cuentas por cobrar en la compañía Aquasport S.A.C. 2017-2018, de acuerdo a la metodología de proyección del estado de situación financiera, estado de ganancias y pérdidas y presupuestos, en los periodos 2020-2024, empezando con el análisis de los estados financieros de la compañía.

El estudio de investigación se realizó bajo el enfoque mixto, de la misma manera el sintagma fue holístico, el tipo de investigación fue proyectiva, asimismo el nivel fue comprensivo y el método fue deductivo. La población fue de 20 personas colaboradores de la compañía, seleccionando una muestra de 3 personas, trabajadores directos relacionados al tema de investigación. Las técnicas que se usaron fueron entrevista y análisis documental, y los instrumentos fueron guía de entrevistas y guía de análisis documental, también los análisis de datos fue la aplicación de análisis vertical y horizontal, además las ratios de liquidez, solvencia, gestión, rentabilidad. Finalmente, para la triangulación de datos se desarrolló mediante el software Atlas.ti.8.

Los resultados señalan que las cuentas por cobrar son deficientes, la compañía necesita reestructurar las políticas y procedimientos de cobranzas, realizar flujo de caja para controlar el efectivo, además la implementación de estrategias financieras para gestionar los cobros de manera eficiente, del mismo modo realizar presupuestos de ventas y cobranzas, de esta manera trabajar en base a objetivos, en conclusión, lograr resultados eficientes.

Palabras claves: Cuentas por cobrar, ratios financieras, análisis financieros, cobranzas, políticas y procedimientos de cobrar.

Abstract: The objective of this research is to propose financial strategies to improve the accounts receivable in the company Aquasport S.A.C. 2017-2018, according to the projection

Esta obra se comparte bajo la licencia Creative Common Atribución-No Comercial 4.0 International (CC BY-NC 4.0) 
methodology of the statement of financial position, profit and loss statement and budgets, in the terms 2020-2024, beginning with the analysis of the financial statements of the company.

The research study was carried out according to the mixed approach, the syntagm was holistic, the type of research was projective, the level was comprehensive and the method was deductive. The population included 20 employees of the company, 3 people were selected as sample, direct workers related to the research subject. The techniques used were interview and document analysis and the instruments were interview guide and document analysis guide; furthermore, the data analysis was the application of vertical and horizontal analysis, as well as the liquidity ratios, solvency, management, profitability. Finally, the Atlas.ti.8. software was used for the data triangulation.

The results indicate that the accounts receivable are deficient, the company needs to restructure the collection procedures and policies, carry out the cash flow to monitor the cash, in addition to the implementation of financial strategies to manage the collections efficiently. Besides, to make use of sales and collection budgets and work on the basis of a goal-oriented approach. To conclude, achieve efficient results.

Keywords: Accounts receivable, financial ratios, financial analysis, collections, collection procedures and policies.

\section{Introducción}

Los problemas que aquejan en las entidades del país de Ecuador-Encalada son que no se tiene una área de control interno, por lo que es clave para la organización, por la cual la cartera no retorna, en consecuencia la liquidez no será la que se espera, por último se concluyó que en la organización no se lleva de manera adecuada el análisis de los ratios financieros en consecuencia, existe desorden en otorgamiento de ventas al crédito y alta morosidad. Así mismo la compañía Aquasport comparando el año 2017 con el 2018 las cuentas por cobrar aumentaron en $142 \%$, rotando cada 15 veces, lo ideal sería entre 6 a 12 veces al año, lo cual hace que las cuentas por cobrar sigan en aumento.

En Perú ciudad de Lima los gerentes de finanzas no llevan de manera adecuada las cuentas por cobrar, los días de pago no están de la mano con los días de cobro, esto por la falta de capacitación al personal de finanzas y compromiso, la empresa Aquasport SAC, no cuenta con personal capacitado para el área de finanzas, así como también no se presupuestan cuanto se tiene que cobrar mensual o anual, no se elaborar flujo de caja y estados de flujo de efectivo, la cobranza no se realiza a diario después de vencida, es por esto que la partida más elevada es las cuentas por cobrar.

El objetivo principal de la investigación es proponer estrategias para mejorar las cuentas por cobrar en la Compañía Aquasport SAC.

Esta obra se comparte bajo la licencia Creative Common Atribución-No Comercial 4.0 
Asimismo, la justificación teórica está sustentada por las teorías antes mencionadas en los párrafos anteriores, son de suma importancia para el desarrollo del problema, lo cual emitirán ideas y conceptos, en consecuencia generara reflexión a los estudiantes y los interesados del tema desarrollado, asimismo estas teorías aportan ideas para solucionar los problemas de las compañías y adquirir nuevos conocimientos de temas relacionados, siguiendo será de utilidad para posibles investigadores en el tema desarrollado, con esta investigación se espera ayudar a las compañías a encontrar posibles soluciones a un problema de cuentas por cobrar, también la justificación metodológica se investiga para ayudar a proponer una solución en base a hechos reales.

\section{Marco teórico}

Se utilizó cinco teorías las que sostienen la indagación, una de ellas la teoría clásica de la administración acreditada por Fayol, Urwick y Gantt describen que la importancia del acto de administrar una compañía, es planear, organizar, controlar, dirigir y coordinar, por lo tanto, la teoría clásica permitirá el uso correcto de estos pasos para la mejora y cumplimiento de los objetivos. Además, esta teoría es importante para el desarrollo administrativo dentro de una compañía, la administración se debe llevar de manera integrada y en conjunto para el resultado de la visión de la compañía. Grantt revela que al personal se debe estimular con incentivos monetarios, de este modo los trabajadores pondrán mucho énfasis a crecer y escalar profesionalmente (Chiavenato, 2007; Medina y Ávila, 2002; Barreno, 2019; Castrillon, 2014).

En segundo lugar, La teoría de la gestión financiera acreditada por Hernández, Espinosa, Salazar, Flores, Guerrero, Puente, Solís, Guerra, Torres y Carrasco manifiestan que el ciclo de cobros es considerado como el tercer paso para que se convierta en efectivo, es decir hace referencia al tiempo que acontece entre las operaciones económicas; venta al crédito de productos o servicios, por lo mismo el cobro de los mismos. Este ciclo reconoce la concentración en el mercado para la venta de la nueva mercadería producida por la compañía y el cobro de la misma, el ciclo termina en la entrada del cash. La intervención de las disciplinas como la economía, la matemática, la estadística, entre otras han facilitado el avance hacia el conocimiento financiero. La planificación estratégica es como asignar y mantener el capital en una compañía, realizando maniobrar que ayuden a llevar al éxito a las compañías, por ultimo planear la estructura financiera de la compañía es obtener y mantener los recursos de la compañía para el nivel de activos establecidos, con fuentes de financiamiento de corto, mediano y largo plazo, por lo que se debe tener conocimiento en el tema financiero, asimismo mantener buenas relaciones con las entidades bancarias (Hernández, Espinosa y Salazar, 2014; Flores, 2008; Guerrero, 2003; Puente, Solís, Guerra, Torres y Carrasco 2017).

En tercer lugar, esta, la teoría del desarrollo organizacional avalada por los autores principales Reddin, Lawrence, Lorsch y Lewin avala la importancia de su aplicación dentro de una organización, por lo que los administradores deben ser eficaces para resolver problemas dentro de una organización, en consecuencia, tendrán una organización ordenada y bien definidos sus objetivos. Lo resaltante de esta teoría es que las personas dentro de un grupo organizacional siempre habrá confrontaciones, por consiguiente tienen que intercambiar y

Esta obra se comparte bajo la licencia Creative Common Atribución-No Comercial 4.0 International (CC BY-NC 4.0) 
discutir ideas con intención de buscar una solución y cumplir los objetivos planteados, por esta razón que todas las organizaciones deben proponer el cambio comenzando por la cabeza principal, por la cual se lograra una organización planificada y bien estructura con mejoras continuas que lograran el éxito (Lewin, 2007; Reddin, 2007; Lawrence y Lorsch, 2007).

En cuarto lugar esta, la teoría general de sistemas sustentada por Von, Boulding, Marcelo y Osorio avalan la importancia dentro de una organización, por lo que implementar la tecnología, en este caso un software de cobranzas ayudara a facilitar y tener en tiempo real la información administrativa-contable en la compañía, así como también permite facilitar y ordenar la administración de la pesquisa de hecho automatizar, aproximar y representar la realidad , así como también promueve la formalidad dentro de una compañía desde adentro, (Chiavenato, 2007; Hernández, 2010 ; Marcelo, 1998).

Por último, la teoría de la contabilidad y el control avalada por los autores Sunder, Gomez, Chacon y Caribano, manifiestan que el control en las compañías es un balance equilibrado entre los intereses de los individuos y las empresas que están formalizaos por contratos, lo cual ambas partes trabajan para sobresalir en el mercado marcando la diferencia. Asimismo, las relaciones que hay entre los gerentes e inversionistas son problemáticas dado que tienen intereses diferentes, es por esto que debe existir el control y las buenas relaciones entre todos los involucrados en una compañía para conocer cuál es el manejo de cada uno y entenderlo de otra perspectiva. La contabilidad son las transacciones que realiza la compaña en uno o varios periodos, con el único objetivo de realizar los instrumentos información financiera, empezando por el estado de situación financiera, lo cual detalla la situación económica en que se encuentra la compañía, asimismo el estado de resultados, lo cual detalla las ventas y gastos asi como también la utilidad de la empresa. Del mismo modo, la contabilidad es una disciplina de naturaleza económica que detalla la información financiera para conocer el presente frente al fututo de la realidad económica en términos cuantitativos, con el fin de que los gerentes encargados de la compañía puedan tomar decisiones financieras y planificar los presupuestos que ayuden a sostener la economía de la compañía (Sunder, 2005; Gomez, 2005; Chacon, 2007; Caribano, 1998).

Continuando, la descripción de la categoría general las cuentas por cobrar, es la agrupación de subcuentas que simbolizan los exigibles por cobrar a los clientes que provienen de los servicios y ventas de acuerdo al giro del oficio que se desarrolla la organización de acuerdo al giro del negocio al que está relacionado, del mimo modo sucede con los accionistas y trabajadores, esto debido a préstamos solicitados, así como también están relacionadas con las decisiones financieras- económicas de una compañía, por lo tanto son un derecho de cobre de la compañía hacia sus clientes deudores., también es importante señalar que los cobros forman parte de créditos que otorga las compañía a sus clientes, que puede ser a corto o largo plazo, de acuerdo a las políticas de cada organización (Ministerio de economía y finanzas 2019; Vargas 2003; Revelo 2013; Fernández 2019; Hernández, 2016) 


\section{Materiales y Método}

Por otra parte, el enfoque es mixto lo cual el indagador usa técnicas de cada uno por separado, haciendo entrevistas y realizando encuestas para conocer las ideas de cada cual. Además, se trazan lineamientos sobre las políticas a imitar según las personas que participan, etc., Así mismo, esas encuestas pueden ser valoradas en escalas medibles y se realizan valoraciones numéricas de las mismas, obteniendo rangos de valores de respuestas, observando las frecuencias, tendencias conseguidas, se hacen histogramas y se formulan hipótesis que serán corroborados posteriormente (Cortés y Iglesias, 2004).

Continuando en la investigación el sintagma fue holístico lo cual permitirá implementar propuestas, asimismo es un procedimiento completo, organizado e integrador, para trabajar procesos que tienen que ver con los inventos, expresar propuestas originales, considerando la creación de modelos y teorías (Hurtado, 2000)

\section{Población, muestra y unidades informantes}

El autor Rodríguez (2005), define la población como el grupo de personas u objetos seleccionados para obtener la muestra en una investigación, por lo consiguiente la población para este trabajo de investigación fue de 20 colaboradores de la Compañía Aquasport SAC. Siguiendo el autor Rodríguez (2005), describe que la muestra es un compuesto o parte del planeta o población en la que se llevara a cabo el trabajo de investigación, por medio de procesos para obtener la cantidad de elementos de la muestra, por lo tanto, la muestra es de 3 colaboradores encargados de las áreas directas el problema de investigación.

Las unidades informantes seleccionadas son cuatro, una de ellas es el Contador General, lo cual es el encargado de la presentación y análisis de la información financiera contable a la organización, asimismo el asistente contable es el encargado de asistir al contador general como también ejecuta los registros contables de todo el movimiento contable en el sistema, siguiendo, la asistente de cobranzas es la responsable de los pagos y cobros en la entidad, así como también los estados financieros son documentos requeridos por la gerencia para tomar decisiones importantes, asimismo detalla la realidad contable financiera de la compañía.

\section{Resultados}

En el análisis horizontal se determinó que el efectivo equivalente de efectivo obtuvo un incremento del $67.61 \%$ en el 2018 con respecto al 2017, esto se dio a que las ventas aumentaron, como también los cobros respectivamente, asimismo en las cuentas por cobrar comerciales terceros se dio un incremento del $142.11 \%$ respecto al 2017 , por otra parte en las cuentas por cobrar al personal, directores, etc. disminuyo en un $94.41 \%$ con respecto al 2017 , del mismo modo las cuentas por cobrar diversas - partes relacionadas en el 2018 aumentaron el $6.11 \%$ respecto al 2017, por otra parte las cuentas por pagar comerciales - terceros en el 2018 aumentaron a $261.51 \%$ con respecto al 2017 , esto se debe a que se compró más mercadería en comparación al 2017, asimismo las cuentas por pagar diversas - terceros en el año 2018

Esta obra se comparte bajo la licencia Creative Common Atribución-No Comercial 4.0 International (CC BY-NC 4.0) 
aumento un $39.42 \%$ respecto al 2017 esto debido que las mercaderías aumentaron en gran cantidad en relación al 2017, continuando el análisis vertical en el 2018 el total del activo corriente representa un 65\% del total del activo, mientras tanto en el 2017 representaron el $62.73 \%$, asimismo cabe indicar que en el 2018 el total del patrimonio neto representa el 62.73 del total de pasivo y patrimonio neto, mientras tanto en el 2017 representa el $59.31 \%$, esto se dio a que las ventas aumentaron y la utilidad aumento por lo tanto el patrimonio también aumenta.

El ratio de liquidez general en relación al 2017 muestra, que por cada s/.1.00 por pagar, existen s/.3.62 por cobrar, en cambio en el 2018 refleja que cada s/.1.00 por pagar, tiene 2.63 por cobrar, cuanto mayor sea el importe de este indicador, mayor será la capacidad de la organización de cancelar sus deudas, también se puede entender que tiene fondos ociosos, se recomendaría mantenerse y seguir en aumento continuo.

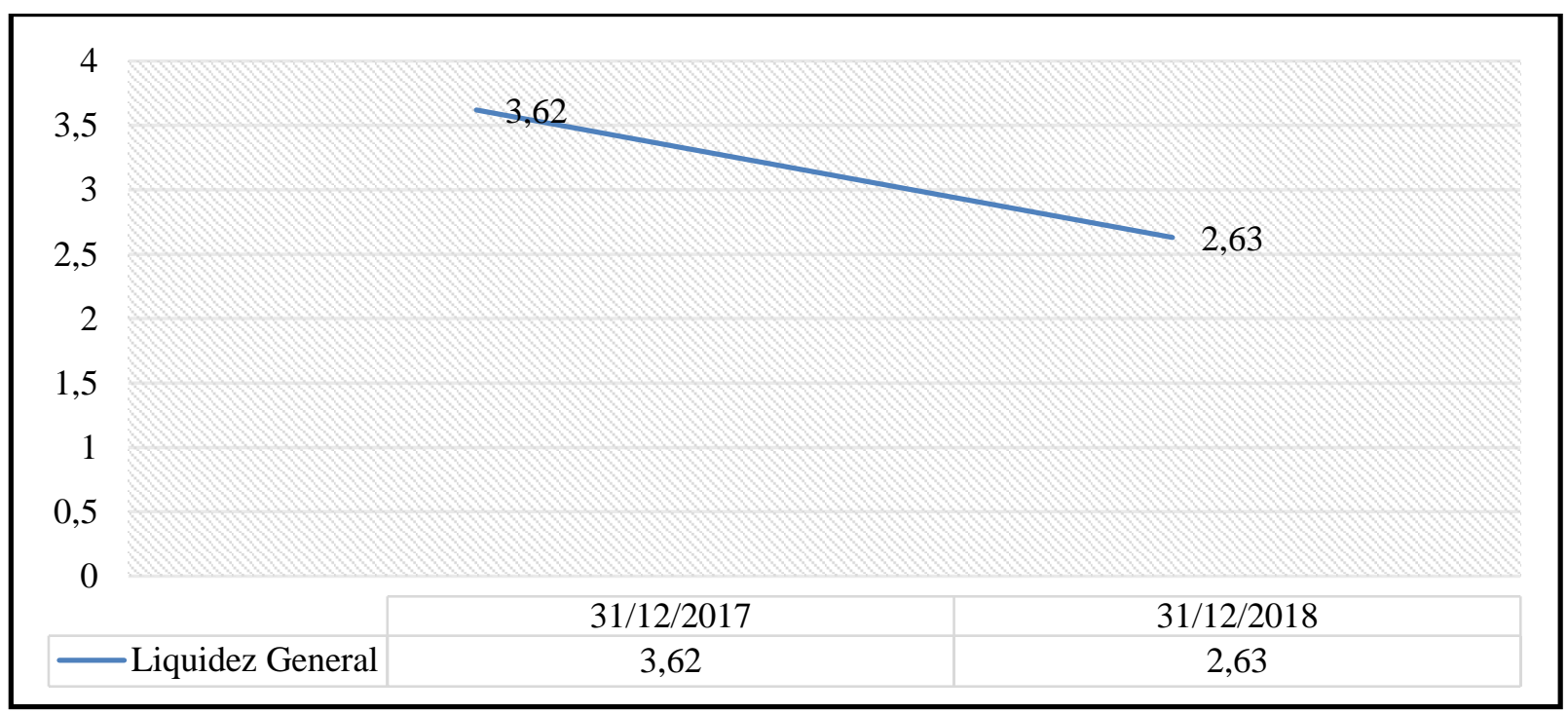

Figura 1. Tendencia del ratio liquidez general Fuente: Elaboración propia (2019)

En la figura 2, la prueba acida al igual que la ratio de liquidez general mide la liquidez en una compañía, sin tomar en cuenta las mercaderías. En el año 2017, esta ratio se ha disminuido moderadamente con un índice de 1.90 y para el año 2018 con 1.05 , lo cual indica que la compañía no está supeditada para pagar los pasivos a corto plazo sin necesidad de vender las mercaderías, lo recomendable seria agilizar las cuentas por cobrar y la vez tener un control exacto de los inventarios. 


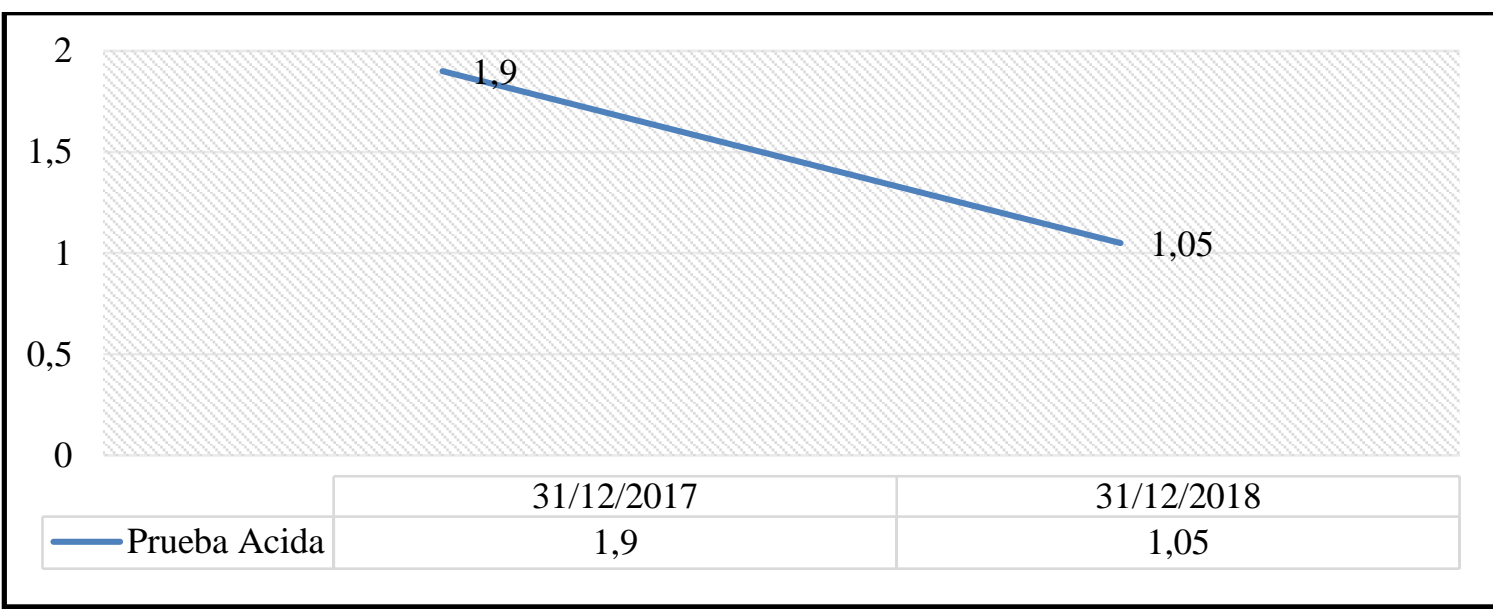

Figura 2. Tendencia de la ratio prueba ácida.

Fuente: Elaboración propia (2019)

En la tabla 3 y la figura 3, los ratios de solvencia con respecto al grado de endeudamiento en el periodo 2017 al 2018, la ratio varió de $41 \%$ a solo el $37 \%$ del activo total, lo cual quiere decir que este indicador está dentro del valor ideal, también es necesario seguir en aumento ya que en el 2018 disminuyo por lo que no podría endeudardarse por el momento.

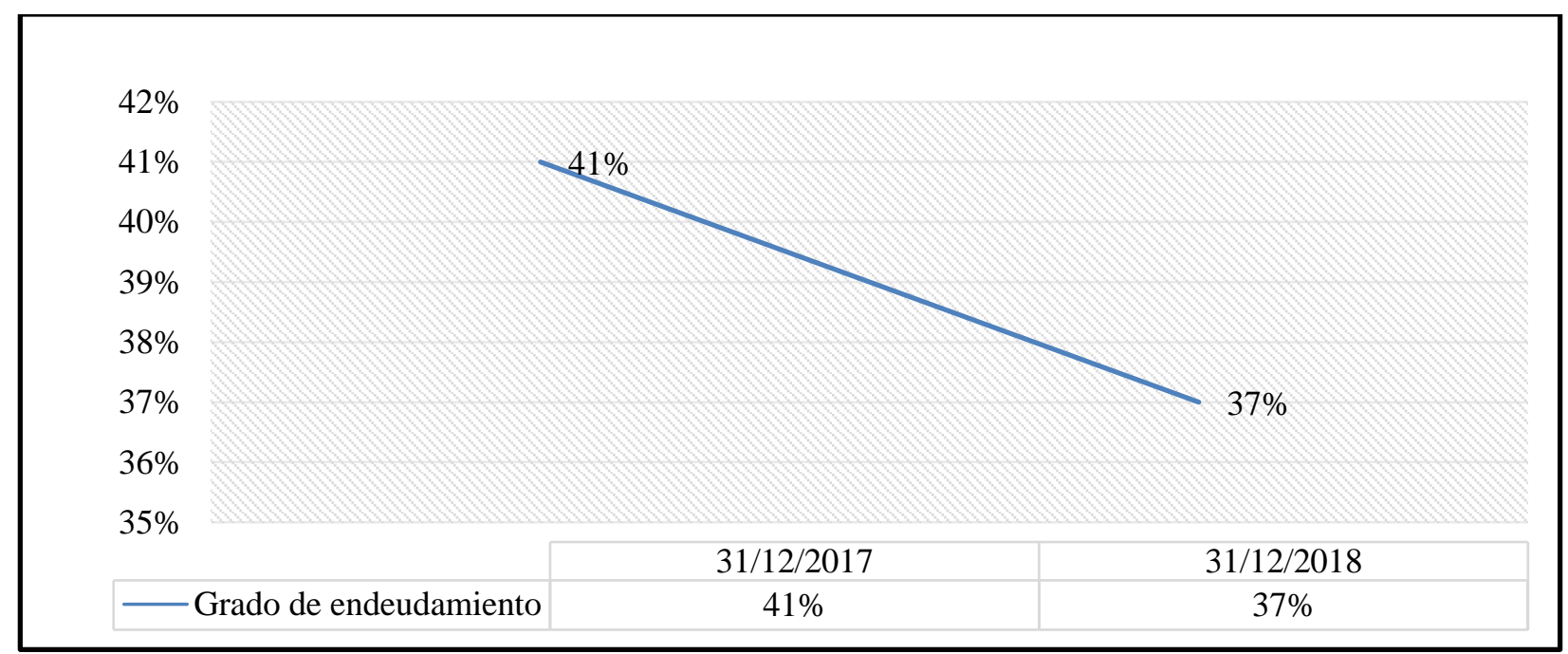

Figura 3. Tendencia del ratio grado de endeudamiento.

Fuente: Elaboración propia (2019)

En la tabla 4 y la figura 4, continuando, el ratio de solvencia con relación al grado de endeudamiento a corto plazo en el 2018 refleja que las deudas del pasivo corriente equivalen al $40 \%$ en relación al patrimonio neto; lo cual nos indica que la compañía está en el rango ideal, por lo mismo que cuenta con recursos para trabajar y también para poder endeudarse.

Esta obra se comparte bajo la licencia Creative Common Atribución-No Comercial 4.0 International (CC BY-NC 4.0) 


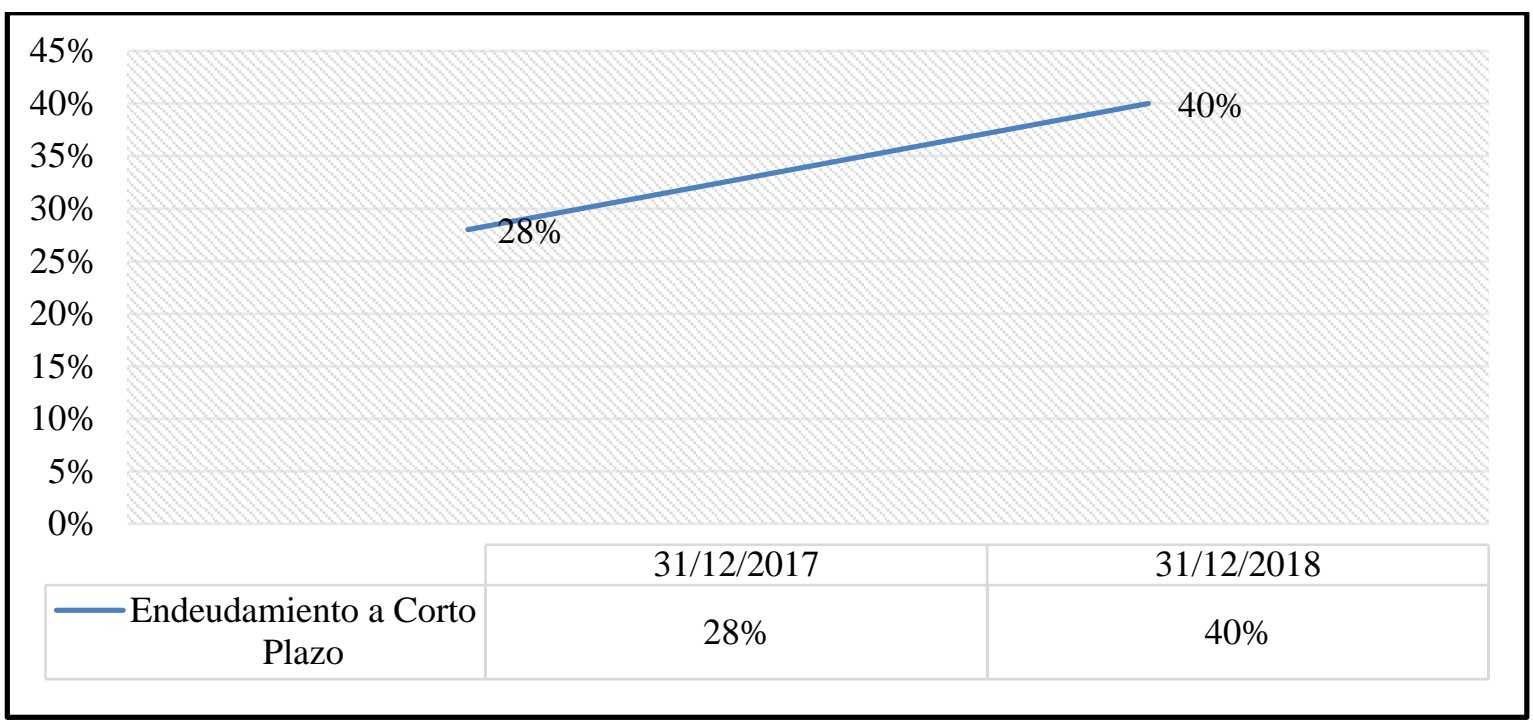

Figura 4. Tendencia del ratio grado de endeudamiento a corto plazo.

Fuente: Elaboración propia (2019)

En la tabla 5 y la figura 5, por otro lado, el endeudamiento patrimonial refleja, que por cada UM aportada por el dueño(s), hay unidad Monetaria 0.69 centavos o el $69 \%$ aportado por los acreedores, asimismo en el 2018 ha disminuido a 0.59 centavos o el $59 \%$, por lo tanto, nos indica que el financiamiento con terceros va disminuyendo año a año mitigando ese riesgo y no exponer a la compañía.

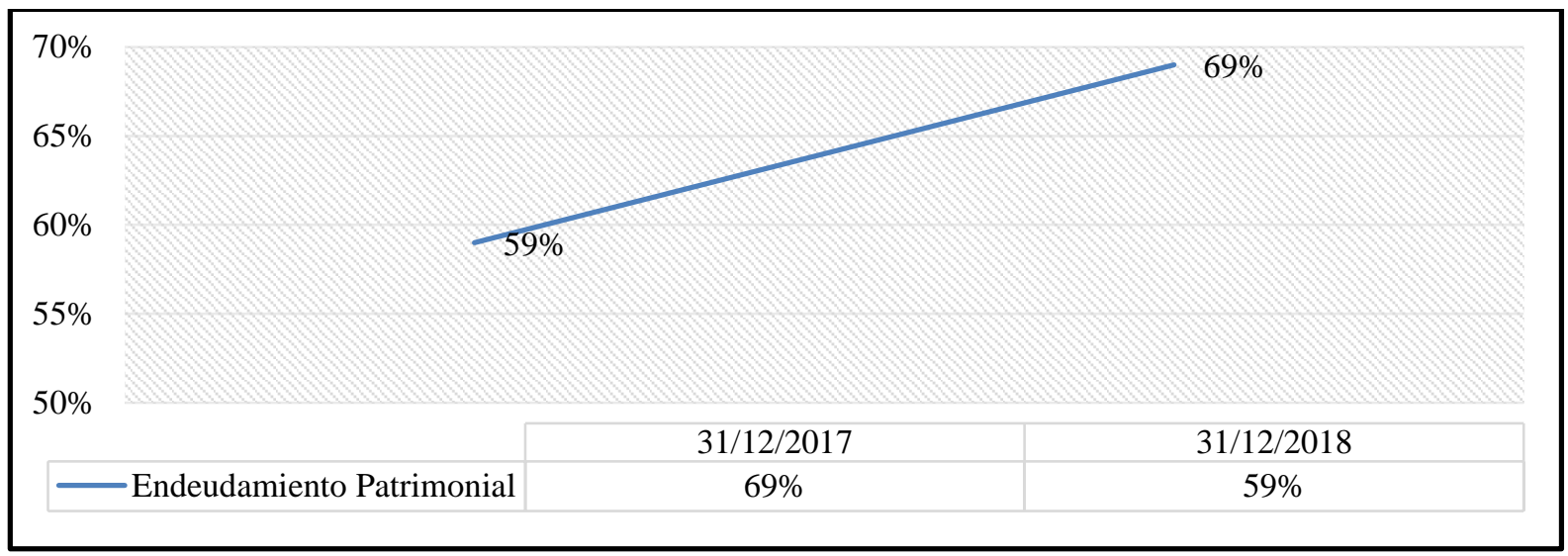

Figura 5. Tendencia del ratio de endeudamiento patrimonial.

Fuente: Elaboración propia (2019)

Esta obra se comparte bajo la licencia Creative Common Atribución-No Comercial 4.0 International (CC BY-NC 4.0) 


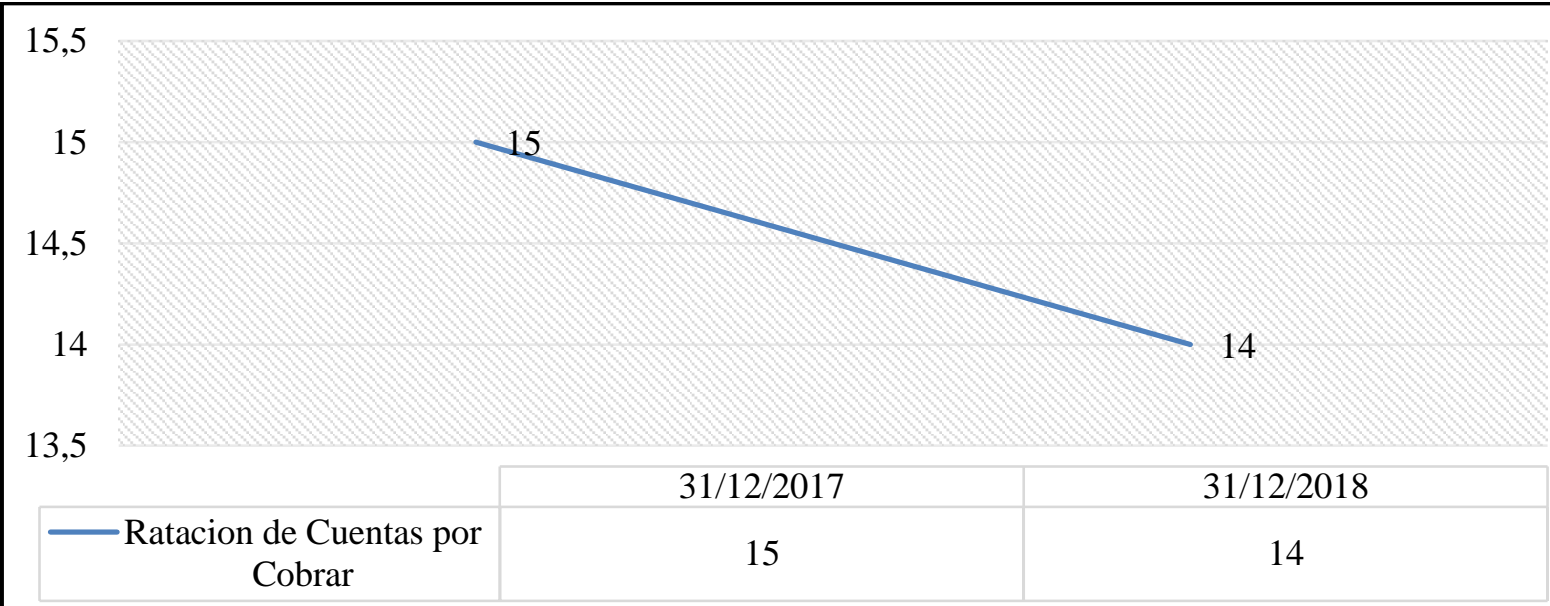

Figura 6. Tendencia del Ratio de Rotación de cuentas por cobrar.

Fuente: Elaboración propia (2019)

En la figura 7, como complemento al ratio de rotación de cuentas por cobrar, nos indica que la empresa cobra cada 24 días, lo cual si lo comparamos con el periodo posterior observamos una caída mínima respecto a los rangos de cobro por días de 2017. Es necesario replantear los procesos y políticas de cobranzas.

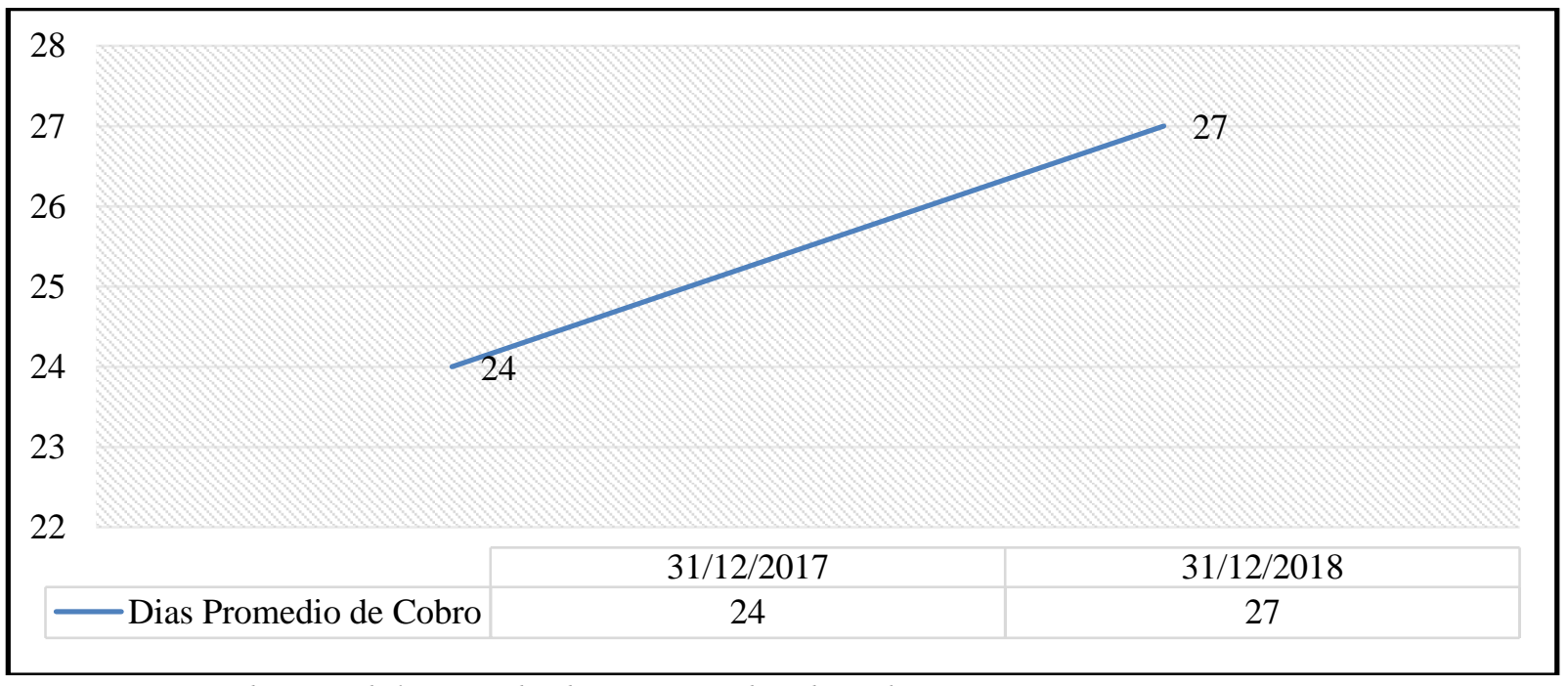

Figura 7. Tendencia del ratio de días promedio de cobro.

Fuente: Elaboración propia (2019)

Esta obra se comparte bajo la licencia Creative Common Atribución-No Comercial 4.0 International (CC BY-NC 4.0) 


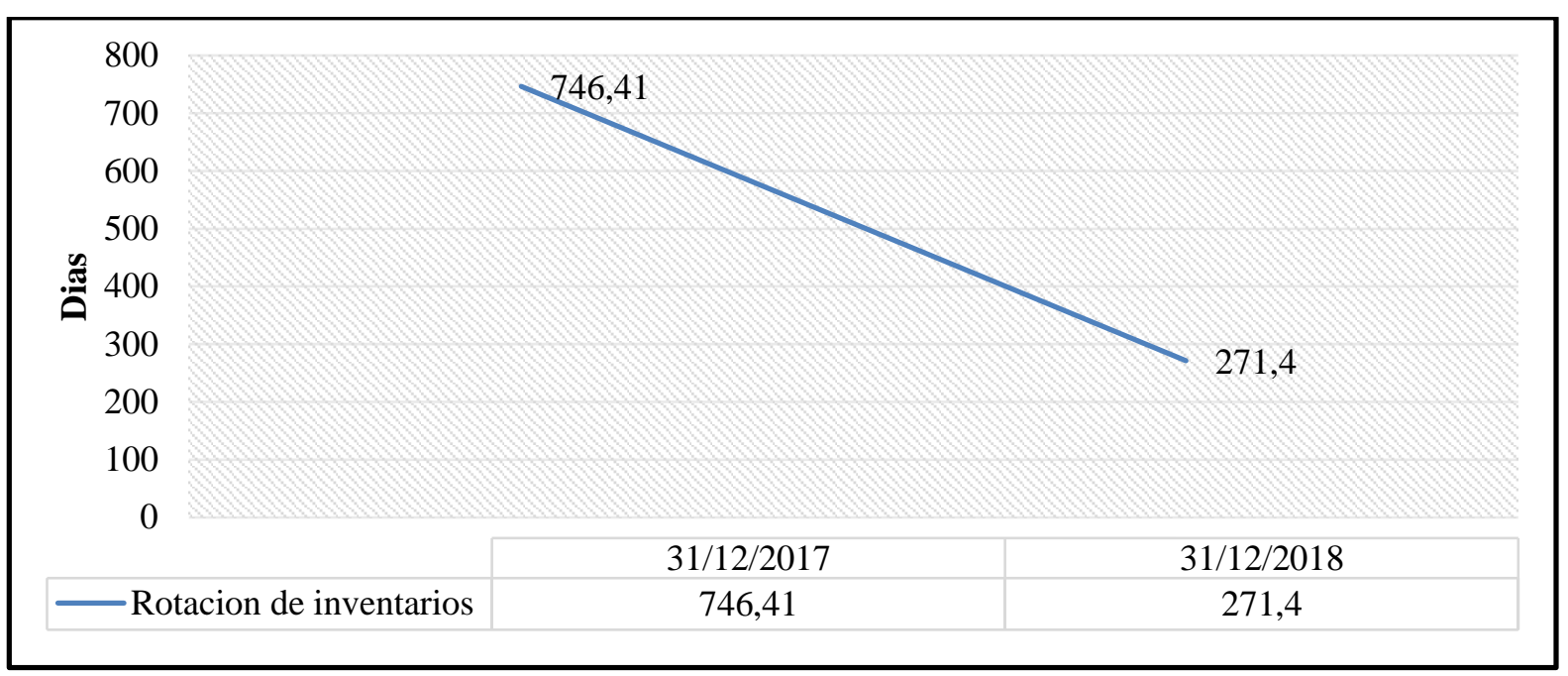

Figura 8. Ratio de rotación de inventarios.

Fuente: Elaboración propia (2019)

En la figura 8, por otro lado la rotación de inventarios nos indica que desde el periodo 2017 esto quiere decir que los inventarios van al mercado cada 746 días, lo que demuestra una baja rotación de esta inversión, en este caso 0.48 veces al año, en cambio en el 2018 ha disminuido considerablemente a 271 días, por lo cual sigue siendo baja la rotación de inventarios con 0.75 veces al año lo cual nos indica deficiencia en el uso óptimo de los recursos de la compañía en ambos años.

\section{Ratios de Rentabilidad}

En la tabla 9 y la figura 9, como podemos observar, en el 2017, el ROA ha disminuido considerablemente, ese año significó poco crecimiento en el mercado lo cual nos tuvo menos ventas. También observamos que el mejor año para la compañía fue el 2018 en el cual, por cada sol en el activo, este produjo un $9.37 \%$ de rendimiento sobre la inversión.

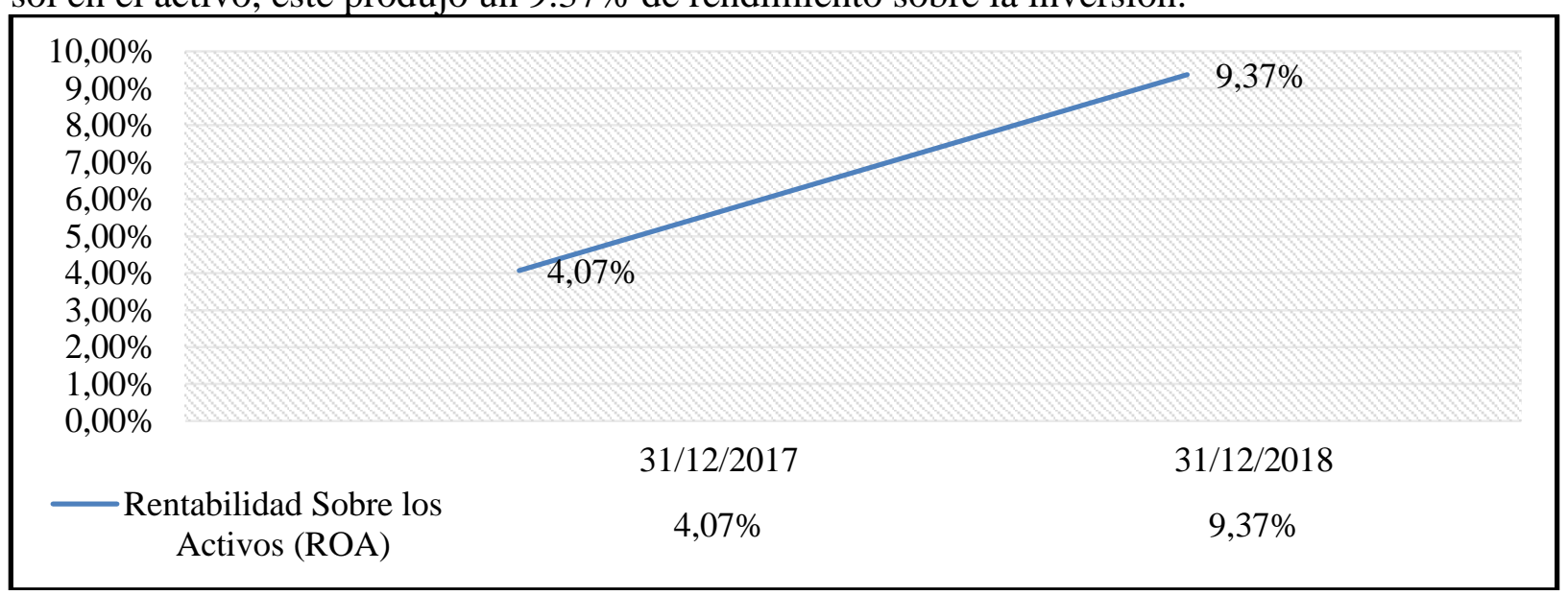

Figura 9. Tendencia del ratio de rentabilidad sobre los activos (ROA).

Fuente: Elaboración propia (2019)

Esta obra se comparte bajo la licencia Creative Common Atribución-No Comercial 4.0 International (CC BY-NC 4.0)

Revista Trimestral del Instituto Superior Universitario Espíritu Santo 
En la figura 10, siguiendo la tendencia del ROA, observamos que su pico de rendimiento sobre el ROE fue durante el 2018, teniendo un $14.93 \%$ de rendimiento sobre cada sol invertido de capital. Por el otro lado, el 2017 no les fue tan bien teniendo un rendimiento de $6.87 \%$ sobre la inversión de capital de la compañía.

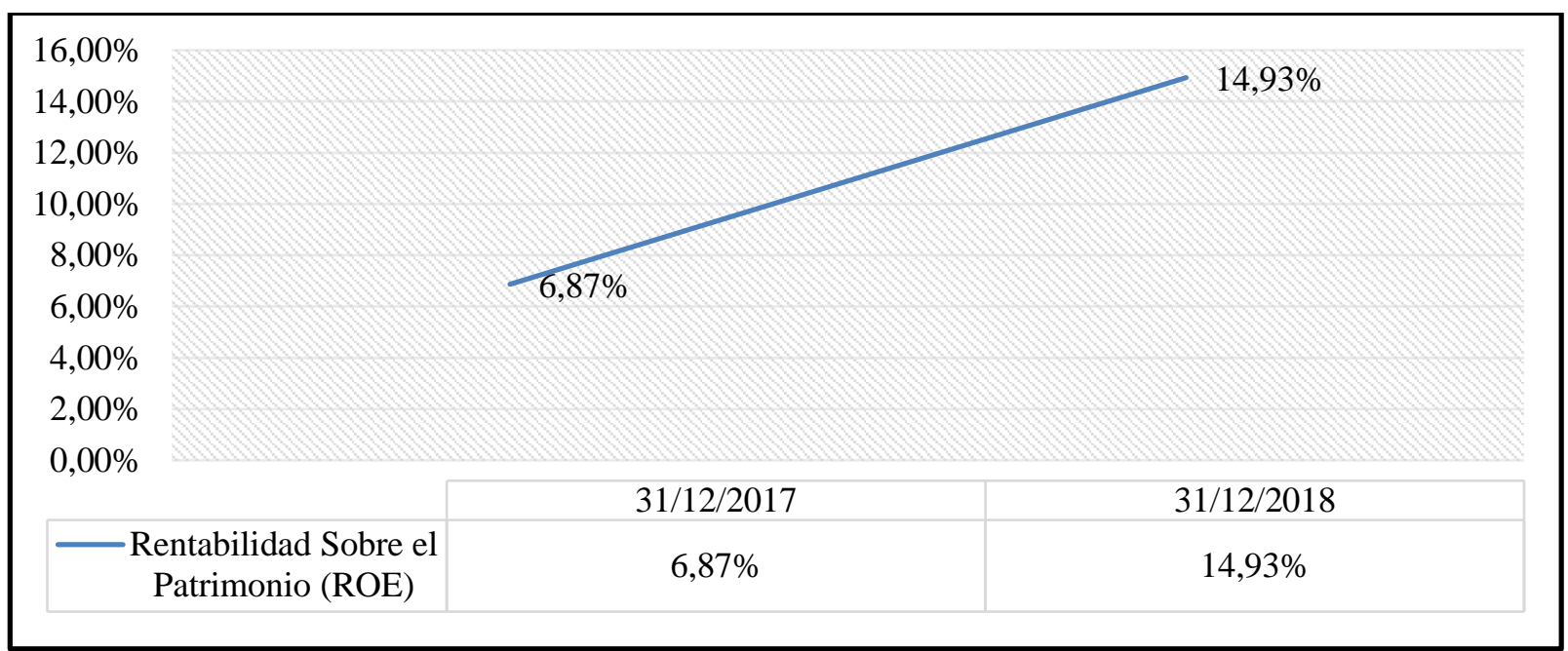

Figura 10. Tendencia del ratio de rentabilidad sobre el patrimonio (ROE).

Fuente: Elaboración propia (2019)

\section{Interpretación}

\section{Resultados cuantitativos}

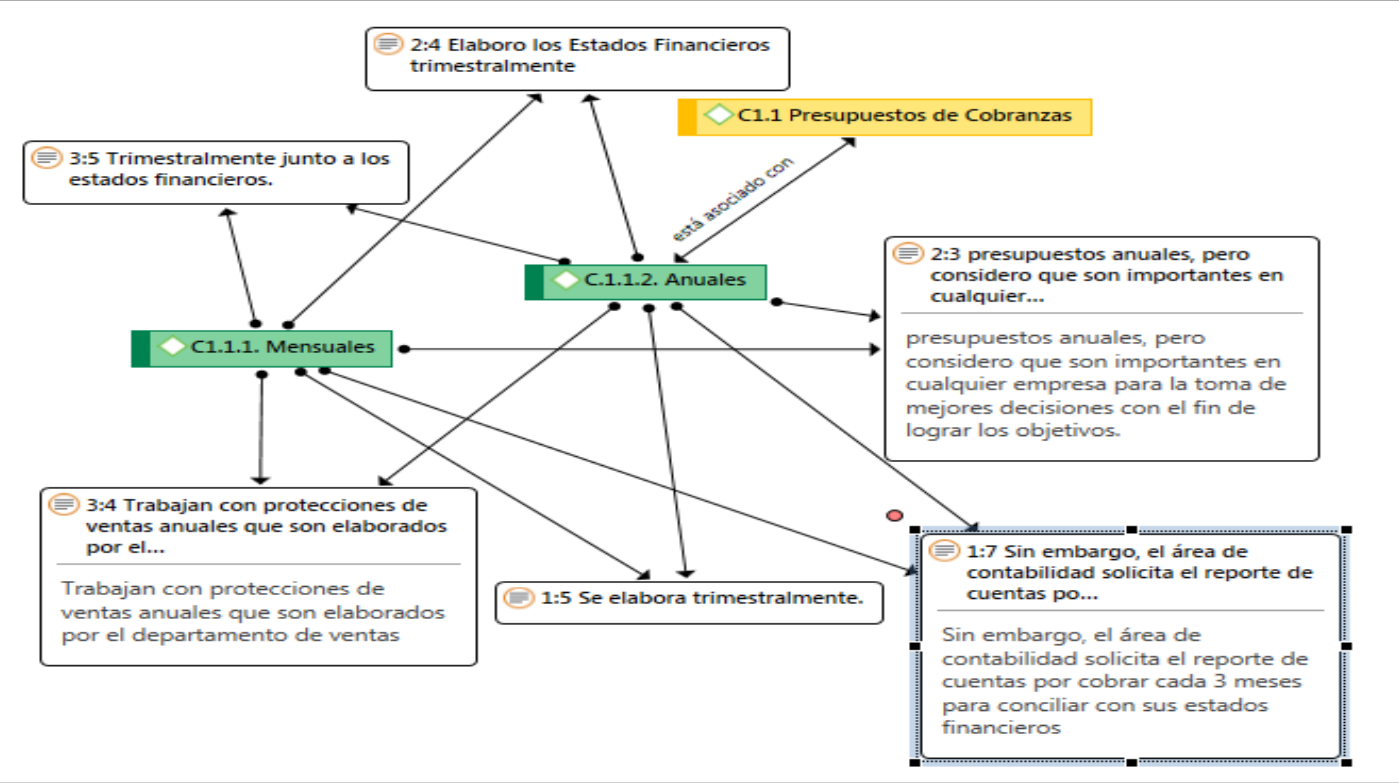

Figura 11. Conclusiones aproximadas de la subcategoría presupuestos de cobranzas.

Fuente: Elaboración Propia (2019)

Esta obra se comparte bajo la licencia Creative Common Atribución-No Comercial 4.0 International (CC BY-NC 4.0)

Revista Trimestral del Instituto Superior Universitario Espíritu Santo 
En la figura 11 que corresponde a la categoría 1, presupuestos de cobranzas teniendo como indicadores mensuales y anuales, la compañía Aquasport S.A.C., no realiza presupuestos mensuales y/o anuales de ventas y cobranzas, por lo tanto, el gerente de finanzas desea implementarlo para obtener logros a corto y largo plazo. Los presupuestos son herramientas financieras de planificación y proyección anticipada de los gastos e ingresos en una compañía, las cuentas por cobrar son partidas importantes, lo cual es necesario implementar presupuestos de ventas, cobranzas y pagos para realizar un manejo más ordenado y confiable. Los presupuestos pueden ser semanales, mensuales o anuales, del mismo modo estos presupuestos son proyectados bajo una comparación con lo ejecutado de acuerdo al tiempo evaluado.

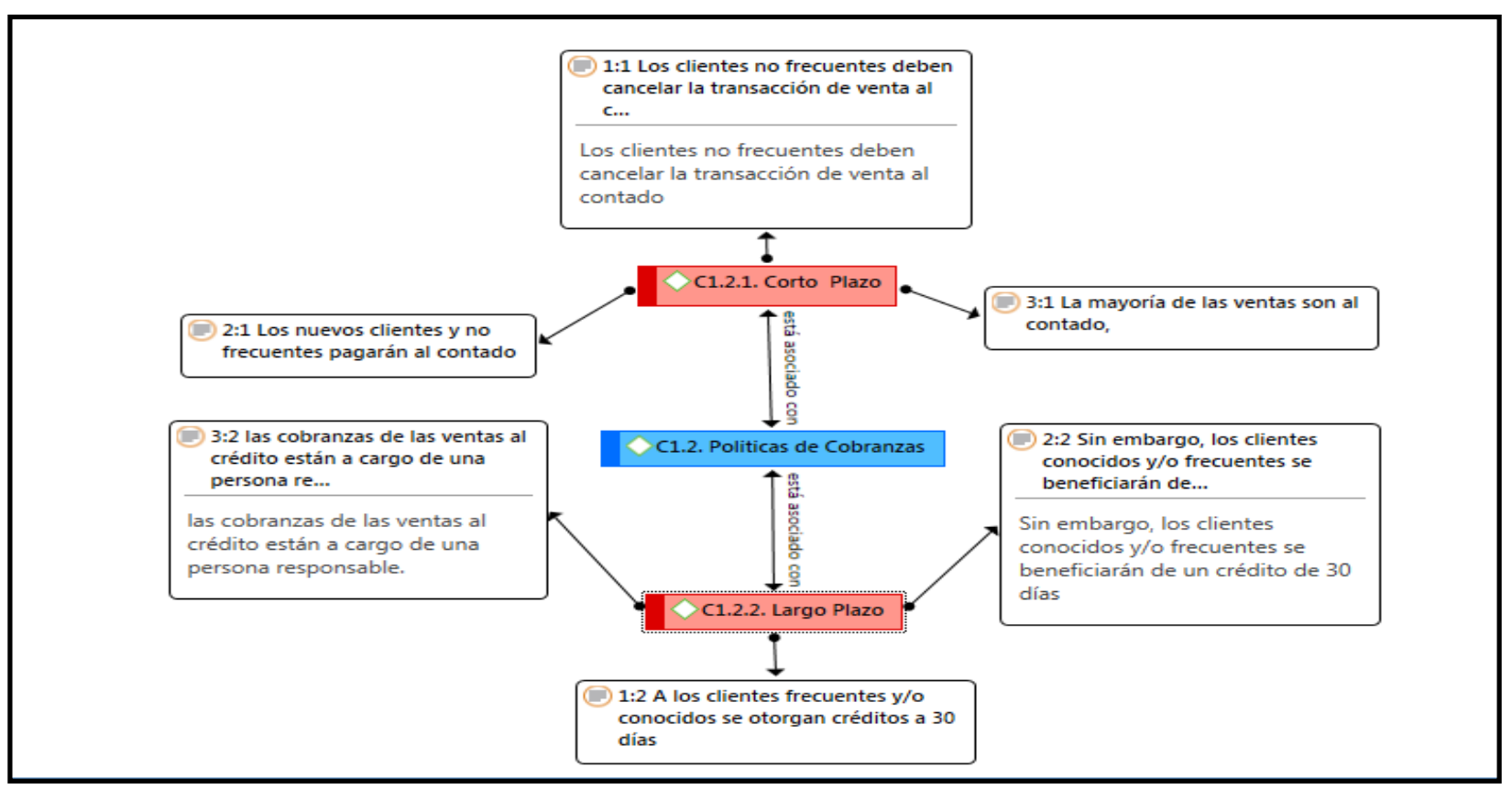

Figura 12. Conclusiones aproximadas de la subcategoría políticas de cobranza.

Fuente: Elaboración propia (2019)

En la figura 12 que corresponde a la categoría 2, Políticas de cobranzas, con los indicadores a corto y largo plazo, la empresa demostró tener políticas de cobranza donde nos dicen que los clientes nuevos deben pagar al contado, así como también, los clientes frecuentes deben pagar a 30 días como máximo, por lo que sería ideal implementar más políticas para que las cobranzas sean efectivas y objetivas. Las políticas de cobranza deben ser procedimientos que ayuden a recuperar la cartera vencida y convertirla en efectivo, para esto es necesario formular estrategias financieras que ayuden a mejorar la rotación de las cuentas por cobrar. Primero se debe evaluar a los clientes el historial crediticio para luego otorgarles el crédito y pactar a cuantos días se debe cobrar. 


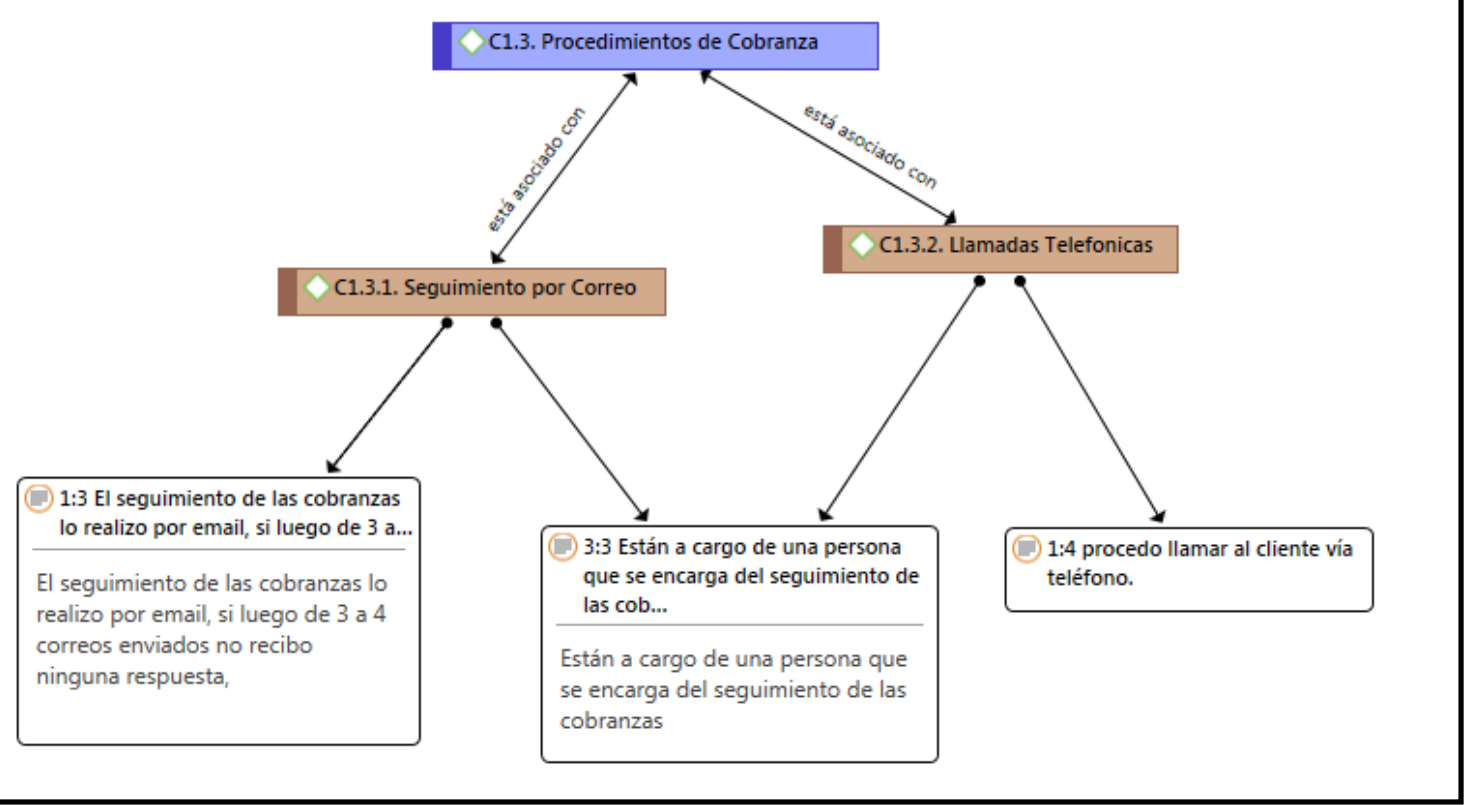

Figura 13. Conclusiones aproximadas de la subcategoría procedimiento de cobranza.

Fuente: Elaboración propia.

En la figura 13 que corresponde a la categoría 3, procedimientos de cobranza, por lo tanto, los indicadores seguimiento por correo electrónico y llamadas telefónicas, lo cual la compañía si tiene procedimientos uno de ellos es que envían entre 3 a 4 cuatro correos no se recibe ningún problema, asimismo el segundo proceso es realizar una llamada telefónica, porque se recomendaría implementar más procedimientos de cobranzas. Los procedimientos que se toman para llevar a cabo las cobranzas dentro de las compañías deben ser de manera minuciosa y con mucha cautela, enviarle correos a diario, así como también llamarlos todos los días y de pronto ofrecerse una negociación que beneficie a ambos.

Esta obra se comparte bajo la licencia Creative Common Atribución-No Comercial 4.0 International (CC BY-NC 4.0) 


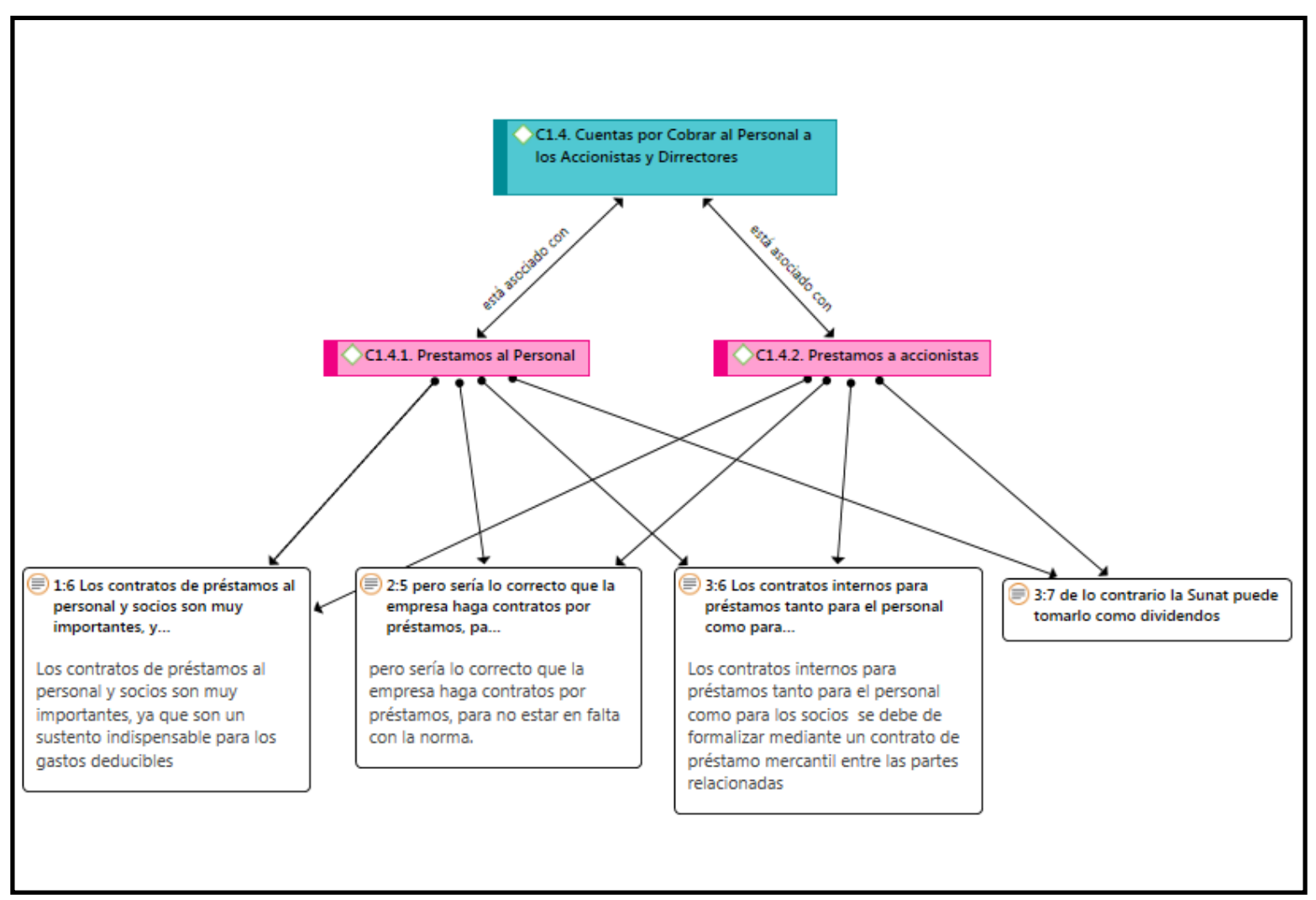

Figura 14. Conclusiones aproximadas de la subcategoría cuentas por cobrar al personal a los accionistas y directores.

Fuente: Elaboración propia (2019)

En la figura 14 que corresponde a la categoría 4, cuentas por cobrar al personal a los accionistas y directores, por lo que los indicadores préstamos al personal y a accionistas, asimismo la compañía no realiza contratos para formalizar los préstamos, por lo cual esto conlleva un desorden en las cuentas por cobrar. Esta partida fue evaluada debido a que tiene un índice elevado, estas cuentas por cobrar fueron evaluadas por Sunat por casi tres años consecutivos por que realizaban prestamos en excesos a los accionistas sin ningún contrato de por medio para sustentar esta operación.

\section{Discusión}

Para la presente investigación titulada "Estrategias financieras para mejorar las cuentas por cobrar, 2017-2018, el objetivo general fue proponer estrategias financieras para mejorar las cuentas por cobrar en la compañía Aquasport SAC, 2017-2018, lo cual se desarrolló una propuesta para darle posibles alternativas de solución al problema.

La compañía requiere mejorar las políticas de cobranza, debido a que no está funcionando de manera efectiva, para ello en la propuesta se reestructuro las políticas de cobranza que se proyectan a que dicha mejora funcione de manera correcta, coincide con Vásquez y Vega, (2016), señalo que la empresa evaluada cuenta con una administración

Esta obra se comparte bajo la licencia Creative Common Atribución-No Comercial 4.0 International (CC BY-NC 4.0) 
desorganizada en las cuentas por cobrar, esto debido a la falta de políticas de crédito, por la que se otorgan al libre albedrío.

Pérez y Ramos (2016), mencionan que la implementación de un sistema de control interno se va a obtener mejoras en las cuentas por cobrar, por lo que la recuperación de los créditos será más efectivo y oportuno, en este caso no coincidimos, necesariamente un sistema de control interno no asegura que la cartera vencida se convierta en efectivo, ya que el control interno se dedica a ver todas las áreas y no una necesariamente.

Los procedimientos de cobranzas, son de suma importancia en una compañía, por lo que permite saber los procesos que se van a tomar en cuenta al momento de realizar el cobro y lograr que este se convierta en efectivo, en la compañía evaluada si cuentas con procedimientos, pero estos no funcionan de manera efectiva porque en el 2018 las cuentas por cobrar aumentaron en $142 \%$ respecto al 2017, esto demuestra el bajo rendimiento en los procesos usados, por lo tanto, coincido con Torres (2017), manifestó que las políticas y procedimientos de cobranzas no se están llevando de manera óptima, por lo cual genera deficiencias en el procedimiento contable y esto también genera problemas en la liquidez.

La elaboración de presupuestos de cobranza proyectados, son herramientas financieras necesarias para trabajar en base a objetivos, por lo tanto, el personal de cobranzas realiza su trabajo a base de proyecciones, en este caso no coincido con Encalada (2016), por que manifiesta que se necesita de un sistema de control para mejorar las cobranzas, porque los créditos no se hacen efectivos a corto plazo.

La aplicación y el análisis de ratios financieros en una compañía son de suma importancia, porque ayuda a conocer el desempeño que va evolucionando mes a mes, asimismo permite que el contador levante las observaciones para dar las recomendaciones adecuadas, coincido con Herrera, Betancourt, Herrera, Rodríguez y Vivanco (2016), mencionan que el análisis financiero por medio de ratios facilita la toma de decisiones para la inversión, financiamiento y planes de acción.

Jaramillo, Armijos y Loaysa, (2018), manifiestan que las cuentas por cobrar reflejan un $54 \%$ de los activos, esto muestra estructura financiera débil, y la carencia en los procedimientos de créditos y cobranzas, además que la persona encargada de cobranzas tiene sobre carga con sus obligaciones, coincido con estos autores, en la compañía evaluada se demostró que las cuentas por cobrar comerciales y las cuentas por cobrar al personal son muy significativas en los dos últimos años 2017-2018, con índices de 142\% y 94.49\% respectivamente, arrojando índices de rotación de cobros de 15 y 14 respectivamente, por lo general las cifras optimas son entre 6 a 12 veces al año, en este caso la compañía demuestra un déficit en los procedimientos y políticas de cobranza, lo cual es urgente restaurar los procesos políticas.

Rivera, Medina, Hernández, Comas y Medina (2017), manifiestan que los ratios son el cociente entre dos masas patrimoniales, uno de ellos el estado de situación financiera y el estado de resultados, se deben seleccionar los ratios idóneos para obtener un análisis efectiva y podar

Esta obra se comparte bajo la licencia Creative Common Atribución-No Comercial 4.0 International (CC BY-NC 4.0) 
dar las recomendaciones del caso, con este autor coincidimos por que la alternativa de solución para mejorar las cuentas por cobrar es realizar ratios financieros para evaluar la situación de gestión en la compañía, normalmente los contadores o los gerentes financieros cada año aproximadamente en marzo describen las mejoras que hay que poner en práctica para que levantar en la compañía, por esto es necesario realizar los análisis horizontales y verticales, como también los ratios y los estados financieros completos sobre todo el estado de flujos de efectivo, que es más importante entre todos y lo que más les interesa a los dueños o accionistas.

\section{Conclusiones}

El análisis financiero realizado a la compañía Aquasport SAC, demostró lo importante que es para la toma de decisiones, del mismo modo permite plantear estrategias para maximizar los errores que están fuera de control en la compañía. Por lo tanto, se analizó que los procedimientos y políticas de cobranzas no están desarrollándose de manera eficiente, debido a la mala gestión de los procesos.

Las ventas de la empresa Aquasport SAC van en sentido creciente, así lo reflejan los estados financieros en los 3 últimos años, a pesar de los cambios económicos en el Perú y la corrupción, sin embargo, las cuentas por cobrar mostraron índices de 142\% en relación al 2017 versus el 2018, también el ratio de rotación de cuentas por cobrar en el 2017-2018, fue de 15 y 14 veces al año, en definitiva, demostró tener deficiencias en las cuentas por cobrar.

Durante el año 2018 las cuentas por cobrar al personal y accionistas disminuyeron en 94.49\% en comparación al 2017, debido a una auditoria de SUNAT que demostró que a los accionistas se les prestaba dinero sin contratos de préstamos, razón por la cual, parte del saldo registrado en dichas cuentas se reclasificaron y pagaron los impuestos correspondientes de dividendos de acuerdo al periodo en operación.

Aquasport SAC, en el análisis vertical del Estado de resultados, la margen bruta fue de $40 \%$ y $66 \%$ en el $2017-2018$, del mismo modo el margen operativo fue $43 \%$ y $19 \%$ en el 2017 2018 , logrando un margen de utilidad de $13 \%$. y $14 \%$ respectivamente.

\section{Referencias}

Aguirre, S. (1995). Entrevistas y cuestionarios. México: Etnografía.

Álvarez, M. (2001). Manual para Elaborar Manuales de Políticas y Procedimientos. México: Panorama.

Ávila, J. (2003). El control interno. Ediciones Habana, 54. Obtenido de

https://www.cipdeso.com/wp-

content/uploads/2018/11/PRESENTACION_AUDITORIA_Y_RESPO_SEPT_2018-min.pdf

Bañuelos, S. (2012). Los errores más comunes en crédito y cobranza. México: Logistic Summit \& Expo. Obtenido de http://www.logisticamx.enfasis.com/articulos/64775-los-erroresmas-comunes-credito-y-cobranza

Barreno, M. (2019). La Universidad Estatal de Milagro vista desde el enfoque de la teoría clásica de la administración. Scielo, 4. doi:ISSN 2519-7320,1990-8644

Bernal, C. (2006). Metodología de la investigación para administración y economía,

Esta obra se comparte bajo la licencia Creative Common Atribución-No Comercial 4.0

International (CC BY-NC 4.0)

Revista Trimestral del Instituto Superior Universitario Espíritu Santo 
humanidades y ciencias sociales (Segunda ed.). México: Pearson Educación.

Brachfield, P. (2003). Cómo vender a crédito y cobrar sin contratiempos. España: Gestión 2000. doi:ISBN: 9788480889612

Camarena, P. (2013). A treinta años de la teoría educativa "Matemática en el Contexto de las Ciencias”. Scielo, 28. doi:ISSN 1665-2673

Campos, L. (2016). Administración Financiera. Unad, 10. Obtenido de https://s3.amazonaws.com/academia.edu.documents/50513625/312540997-

ADMINISTRACION-FINANCIERA-UNAD.pdf?response-content-

disposition=inline \%3B\%20filename\%3DADMINISTRACION_FINANCIERA_UNAD.pdf\&XAmz-Algorithm=AWS4-HMAC-SHA256\&X-Amz-Credential=AKIAIWOWYYGZ2Y53

Caribano, L. (1998). Teoría actual de la contabilidad. Madrid: Universidad Autónoma de Madrid, AECA.

Castrillón, A. (2014). Fundamentos generales de administración. Medellin: Centro Editorial Esumer. doi:ISBN 978-958-8599-67-0

Castromán, J., \& Porto, N. (2005). Responsabilidad social y control interno. Revista Universo Contábil, 17. doi:ISSN: 1809-3337

Chacón, G. (2007). La Contabilidad de Costos, los Sistemas de Control de Gestión y la Rentabilidad Empresarial. Actualidad Contable Faces. doi:ISSN: 1316-8533

Chiavenato, I. (2007). Introducción a la teoría general de la administración (Séptima ed.). México: Mc Graw Hill.

Chumpitaz, D., \& Gonzales, Y. (2013). Caracterización del control interno en la gestión de las empresas comerciales del Perú 2013. Revista Científicas, 10. doi:DOI: http://dx.doi.org/10.21895/incres

Colina, L., \& Cubillán, A. (2012). La planificación presupuestaria en universidades públicas. Centro de Investigación de Ciencias Administrativas y Gerenciales, 2/17. Obtenido de file:///D:/usuario/Downloads/Dialnet-LaPlanificacionPresupuestariaEnUniversidadesPublic$5028137 \% 20(1) \cdot \mathrm{pdf}$

Conexionesan. (2017). Los reportes de tesorería y su utilidad en el manejo financiero. Lima: Conexionesan. Obtenido de https://www.esan.edu.pe/apuntes-empresariales/2017/08/losreportes-de-tesoreria-y-su-utilidad-en-el-manejo-financiero/

Correa, P., \& Eslao, K. (2018). Elaboración de un manual de procedimientos para el departamento de crédito y cobranzas en la compañía Otelo \& Fabell. Revista Observatorio de la Economía Latinoamericana, 4. doi:ISSN: 1696-8352

Cortés, M., Joya, R., Velázquez, J., \& Lepe, B. (2018). Supervisión del control interno en microempresas mexicanas. Scielo, 16. doi:ISSN 2306-9155

Cruz, L. (2013). Evaluación del control interno y su incidencia en la cuentas por cobrar de Foro Miraflor. Revista Científica de FAREM-Estelí., 8. doi:ISSN: 2305-5790

Dextre, J., \& Rivas, R. (2012). ¿Control de gestión o gestión de control? Redalyc.org, 13. doi:ISSN: 1992-1896

Dieterich, H. (1996). Nueva guía para la investigación científica. México Planeta mexicana199229 p. ilus. (ColecciónAriel). Doi: 968-6640-84-3

Dulzaides, M., \& Molina, A. (2004). Análisis documental y de información: dos componentes de un mismo proceso. Scielo. doi:1024-9435

Encalada, L. (2016). Provisión de las cuentas por cobrar y su efecto en los estados

Esta obra se comparte bajo la licencia Creative Common Atribución-No Comercial 4.0 International (CC BY-NC 4.0)

Revista Trimestral del Instituto Superior Universitario Espíritu Santo 
financieros de la Compañia Itnvescom S.A. Tesis de título profesional. Guayaquil: Universidad Laica Vicente Rocafuerte de Guayaquil.

Fernandez, N. (2009). Procedimientos de control interno de las cuentas por cobrar en las empresas de construcción de la industria petrolera. Caso: Municipio Maracaibo. Revista Electrónica de gerencia empresarial, 14. doi:ISSN: 18569706

Fernández, R. (2019). Administración de cuentas por cobrar. Academia.edu, 12. Obtenido de

https://www.academia.edu/15208410/ADMINISTRACI\%C3\%93N_DE_CUENTAS_POR_CO BRAR

Fidias, A. (1999). El proyecto de investigación guía para su elaboración (Tercera ed.). Venezuela: Editorial Episteme. doi:980-07-8529-9

Flores, M., \& Naval, Y. (2016). Gestión de cuentas por cobrar y la rentabilidad de las empresas del sector industrial que cotizan en la. Revista de Investigación Universitaria, 16. doi:DOI:https://doi.org/10.17162/riu.v6i1.1039

Flórez, L. (2008). Evolución de la Teoría Financiera en el Siglo XX. Universidad Católica Popular de Risaralda, 24-24.

Gitman, L. (2003). Principios de administración financiera. México: Pearson educación.

Gonzales, E., \& Sanabria, S. (2016). Gestión de cuentas por cobrar y sus efectos en la liquidez en la facultad de una universidad particular, Lima, periodo 2010-2015. Revista de investigación universitaria, 6. doi:https://doi.org/10.17162/riu.v5i2.975

González, J., \& Castañeda, J. (1992). Contabilidad, finanzas y economía para pequeñas y medianas empresas. Lima: Printed in Peru. Doi: 84-89293

Guerrero, G. (2003). Los retos de la gestión Los retos de la gestión estratégica de las organizaciones y la globalización. Innovar, 3.

Hernández, N., Espinosa, D., \& Salazar, Y. (2014). La teoría de la gestión financiera operativa desde la perspectiva marxista. Scielo, 8. doi:ISSN: 0252-8584

Hernández, R., Fernández, C., \& M, B. (2010). Metodología de la investigación (Quinta ed.). México: McGraw-Hill. doi:ISBN: 978-607-15-0291-9

Hernandez, S. (2010). Introducción a la administración: origen, evolución y vanguardia (Quinta ed.). México: McGraw-Hill. doi:ISBN: 970-10-4219-0

Herrera, A., Betancourt, V., Herrera, A., Vega, S., \& Vivanco, E. (2016). Razones financieras de liquidez en la gestión empresarial para toma de decisiones. Revista de la Facultad de Ciencias Contables, 10. doi:ISSN: 1609-8196

Hurtado, J. (2000). Metodología de la investigación holística. Venezuela: Fundación Sypal.

Jaramillo, M., Armijos, M., \& Loayza, M. (2018). Análisis del control de las cuentas por cobrar en la empresa Sociedad Eléctrica Machala. Conference Proceedings UTMACH, 8. doi:ISSN 2588-056X

Levy, L. (2009). Planeación Financiera en la Empresa Moderna. México: Ediciones Fiscales ISEF. Obtenido de https://books.google.com.ec/books?id=zrjKBSptgdcC\&pg=PA304\&lpg=PA\&hl=es\#v=onepage $\& q \& \mathrm{f}=$ false

López, P. (2004). Población muestra y muestreo. Scielo. doi:1815-0276

Makubikua, V. (2015). Gestión de presupuestos financieros: Determinación de

Esta obra se comparte bajo la licencia Creative Common Atribución-No Comercial 4.0

International (CC BY-NC 4.0)

Revista Trimestral del Instituto Superior Universitario Espíritu Santo 
prioridades en el Hospital Central. Ciencias Holguín. doi:ISSN 1027-2127

Mantilla, S. (2009). Auditoría del control interno (cuarta ed.). Bogotá: ECOE ediciones. Obtenido de https://s3.amazonaws.com/academia.edu.documents/59205261/Auditoria-delControl-Interno-4ed20190510-119834-ugk7y7.pdf?response-contentdisposition=inline \%3B\%20filename\%3DAuditori_a_del_Control_Interno_4ed.pdf\&X-AmzAlgorithm=AWS4-HMAC-SHA256\&X-Amz-Credenti

Marcelo, A., \& Osorio, F. (1998). Introducción a los conceptos básicos de la teoría general de sistemas. Redalyc.org, 12. doi:E-ISSN: 0717-554X

Ministerio de Economía y Finanzas. (2019). Plan contable general empresarial - Mef. Obtenido de Plan contable general empresarial: https://www.mef.gob.pe/contenidos/conta_publ/documentac/PCGE_2019.pdf

Ministerio de Economía y finanzas. (2018). Estado de Resultados. Perú: MEF. Obtenido de https://www.mef.gob.pe/es/contabilidad-publica-sp-6700/388-documentacion/1729-estadode-resultados

Morón, A., Reyes, M., \& Chirinos, U. Á. (2015). Gestión de riesgos en la empresa R.C. Agelvis, C.A. Multiciencias. Doi: 1317-2255

Nogueira, D., Medina, A., Hernández, A., Comas, R., \& Medina, D. (2017). Análisis económico financiero: talón de Aquiles de la organización. Caso de aplicación. Scielo, 10. doi:ISSN 1815-5936

Palacio, R. (2012). Manual de procedimiento para el control de las cuentas por cobrar. Revista Académica de Economía, 8. doi:SSN 1696-8352

Parra, J., \& La Madriz, J. (2017). Presupuesto como instrumento de control financiero en pequeñas empresas de estructura familiar. Revista Científica Electrónica de Ciencias Gerenciales, 33. doi:ISSN: 1856-1810

Peralta, E. (2016). Teoría general de los sistemas aplicada a modelos de gestión. Universidad de Cartagena. doi:DOI 10.22519/22157360.901

Pérez, T., \& Ramos, M. (2016). Implementación de un sistema de control interno en las cuentas por cobrar y su incidencia en la liquidez de la empresa Bagservis SAC, en Trujillo, en el año 2016. Tesis de título profesional. Trujillo: Universidad privada del norte.

Petit, E. (2012). El desarrollo organizacional innovador: un cambio conceptual para promover el desarrollo. Revista de Ciencias Sociales (VE), 1/16. doi:ISSN: 1315-9518

Puente, M., Solís, D., Guerra, C., \& Carrasco, V. (2017). Relación entre la gestión financiera y la rentabilidad empresarial. Revista Contribuciones a la Economía, 3. doi:ISSN: $1696-8360$

Revelo, S. (2013). Sistema de cobro y recuperación de cartera de crédito para la empresa "Profemac" de la ciudad de Tulcán. Tulcán: Universidad Regional autónoma de los Andes. Obtenido de http://dspace.uniandes.edu.ec/bitstream/123456789/3524/1/TUTCYA01821013.pdf

Reyes, A. (2002). Administración de Empresas. México: Limusa.

Rivas, G. (2011). Modelos contemporáneos de control interno. Fundamentos teóricos. Observatorio Laboral Revista Venezolana. doi:1856-9099

Rivas, L. (2007). Mapa de las teorías de la organización: una orientación para empresas. Concyteg, 6-7. Obtenido de http://files.franklin-yagua.webnode.com.ve/2000000901b8c01c03d/MAPA_TEORIAS_ORGANIZACION_ORIENTACION_EMPRESAS.pdf

Esta obra se comparte bajo la licencia Creative Common Atribución-No Comercial 4.0 International (CC BY-NC 4.0) 
Robledo, J. (2009). Observación participante: informantes claves y rol del investigador. Nicaragua: Centro de Investigación Nure.

Rodríguez, D. (2018). Claves para un adecuado cálculo de ratios y análisis de estados financieros. Revista de estudiantes de la facultad de gestión y alta dirección, 10. Obtenido de http://revistas.pucp.edu.pe/index.php/innovag/article/view/20196/20157

Rodríguez, E. (2005). Metodología de la investigación (Primera ed.). México. doi:9685748-66-7

Rodríguez, M., Piñeiro, C., \& de Llano, P. (2013). Mapa de riesgos: Identificación y gestión de riesgos. Atlantic Review of Economics. doi: 2174-3835

Serrano, P., Señalin, L., Vega, F., \& Herrera, J. (2017). El control interno como herramienta indispensable para una gestión financiera y contable eficiente en las empresas bananeras del cantón Machala Machala (Ecuador). Revista Espacios. doi:ISSN 0798101

Sunder, S. (2005). Teoría de la contabilidad y el control. Colombia: Editorial Universidad Cooperativa de Colombia.

Superintendencia Nacional de Aduanas y de Administración Tributaria. (2015). Formulación de los estados Financieros y Presupuestarios de la SUNAT -Captadora. Perú: SUNAT. Obtenido de http://www.sunat.gob.pe/cuentassunat/captacionImpuestos/icontable/2015/pc001-20156R0200.pdf

Torres, J. (2017). Las cuentas por cobrar y su incidencia en la liquidez de la empresa Adecar Cia. LTDA. Tesis de título profesional. Guayaquil: Universidad Laica Vicente Rocafuerte de Guayaquil.

Umasi, B., \& Choquepuma, V. (2016). Tendencia de las cuentas por cobrar y ratios de actividad en la empresa Alpe Corporación S.A. en los periodos 2011-2015. 2-7. Obtenido de https://revistas.upeu.edu.pe/index.php/riu/article/viewFile/722/692

Universidad Esan. (06 de 05 de 2019). Reportes de tesorería: ¿cómo influyen en el manejo financiero? Obtenido de ConexionEsan: https://www.esan.edu.pe/apuntesempresariales/2019/05/reportes-de-tesoreria-como-influyen-en-el-manejo-financiero/

Vargas, H. (2003). Consideraciones prácticas para la gestión del capital de trabajo en las Pymes innovadoras. Revista escuela de administración de negocios. Obtenido de file:///D:/usuario/Downloads/237-Texto\%20del\%20art\%C3\%ADculo-660-1-10-20130727.pdf

Vásquez, L., \& Vega, E. (2016). Gestión de cuentas por cobrar y su influencia en la liquidez de la Empresa Consermet S.A.C., Distrito de Huanchaco, año 2016. Tesis de título profesional. Trujillo: Universidad Privada Antenor Orrego.

Velázquez, R., \& Consuegra, G. (2018). Algunas reflexiones sobre la teoría general de sistemas y el enfoque sistémico en las investigaciones científicas. Scielo. doi:ISSN 0257-4314

Zamora, M. (2017). El desarrollo organizacional como generar un cambio significativo en las organizaciones de la Sociedad Civil. Revista Extremeña de Ciencias Sociales. Obtenido de file:///D:/usuario/Downloads/DialnetElDesarrolloOrganizacionalComoGeneradorDeUnCambioS-6415690.pdf

Esta obra se comparte bajo la licencia Creative Common Atribución-No Comercial 4.0 International (CC BY-NC 4.0) 